\title{
The Extended Synthesis: Something Old, Something New
}

\author{
Daniel R. Brooks
}

Published online: 25 January 2011

(C) Springer Science+Business Media, LLC 2011

\begin{abstract}
The eclipse of Darwinism began to end in the 1980s and hangs in the balance today. We need an Extended Synthesis, using "extension" metaphorically. We must extend back in time to recover important aspects of Darwinism that were set aside, and then lost during neoDarwinism, then move forward beyond neo-Darwinism to encompass new data and concepts. The most comprehensive framework for the Extended Synthesis is the Major Transitions in Evolution. The Extended Synthesis rests comfortably within a philosophical perspective in which biology does not need to be connected with other areas of science in order to justify itself. I am attracted to an older concept in which biology needs a covering law to connect it with the rest of the natural sciences. Darwin implicated a "higher law," but did not specify it. If we can elucidate that law, the Extended Synthesis will become the Unified Theory of Biology called for by Brooks and Wiley 25 years ago.
\end{abstract}

Keywords Extended synthesis · Neo-Darwinism ·

Darwinism · Complexity

We are Man the Hunted, descendants of primates whose cleverness, combined with caution and suspicion, allowed us to survive long enough to begin making the weapons evolution neglected to provide. Once we successfully tested those weapons on species that recently had been fellow prey, we styled ourselves Man the Hunter. At this point, the first elements of self-awareness and its adaptive correlate, denial, emerged. Our suspicious, cautious nature became canalized into superstition, especially relating to the meaning of life and death.

D. R. Brooks $(\bowtie)$

Ecology and Evolutionary Biology, University of Toronto,

Toronto, ON M5S 3G5, Canada

e-mail: dan.brooks@utoronto.ca
By 1982, the centenary of Darwin's death, Niles Eldredge and Steven J. Gould had catalyzed a loosely connected group of evolutionary biologists unhappy with the New Synthesis to unleash a cascade of criticisms and proposals. Emboldened by this display of the scientific community at its meritocratic best, Ed Wiley and I entered the fray. The day we finished proofreading Evolution as Entropy, David Hull presciently warned us the fun was over. Soon, I received an envelope from a friend who had seen a manuscript on a colleague's desk. Such privileged material is rarely copied and forwarded. My friend wrote, "I think you and Ed should know what you're up against." The privately circulated manuscript was authored by three academics at the University of California-Berkeley. Ed and I were stunned by its vicious tone. Why the rhetorical heat? If we were wrong, embarrassed silence would have sufficed. Perhaps we were right, but those in power could not gain credit for themselves by acknowledging us as the formulators-we were young; we were not population geneticists or mathematicians; we were not at powerful institutions; and we had no powerful advocates.

In contrast to the prevailing Kuhnian social model of scientific change, Hull (1988) proposed that most scientists, regardless of age, don't like new ideas, even ones that support their own worldview ("I already know that, why do I need this?"). They will fight to keep new ideas from becoming accepted unless they benefit their own careers. Ambitious scientists denounce new ideas, co-opting them once the originators have been frightened into silence or to marginal publication outlets (e.g., Brooks 1990, 1992, 1994, 1997, 1998, 1999, 2000, 2001a, b, 2002; Brooks and McLennan 1990, 1991, 1997, 2000, 2002, 2011). Eldredge's $(1985,1995)$ fundamental findings about the nature of the New Synthesis were equally bold - it had all the trappings of a marriage of convenience and none of the 
appearances of a consensual union. Thus, the status quo reaction to punctuated equilibrium and the other new ideas was a defense of a sociological arrangement, not of a set of scientific principles.

Hull and Eldredge have largely been proven correct. For example, a prominent ecologist and biogeographer stated in 1986 that Evolution as Entropy collapsed by virtue of the fact that it was absurd to believe there were any phylogenetic influences in ecology and behavior. Phylogeny, Ecology and Behavior (Brooks and McLennan 1991) documented the pervasive phylogenetic influences on all levels of ecology and behavior, stimulating a decade of research substantiating Brooks and Wiley's assertions about historical ecology (Brooks and McLennan 2002). Yet, none of that was seen as corroborating a bold prediction by Brooks and Wiley; rather, the ideas have been co-opted into "the Synthesis" ("we've always believed this"). I think Hull's and Eldredge's assessments were correct but incomplete, because they focused on the rational behavior of the critics. And yet, the reactions were also emotional. At times, people denouncing these new ideas argued against their own published work. So, it was not scientific disagreements but superstition and fear, fear that the new ideas were correct, driving the reactions. What had we - punctuationists, cladists, entropists-done?

I believe we provoked an atavistic reaction to death. We used the centenary of Darwin's death to call for radical change in evolutionary theory. Fellow academics instinctively recoiled from the symbolism of the death of a leader or a religion, fearing chaos and violence would ensue until a new warlord or god appeared to restore order and worrying that the new emergent order would diminish the influence of those previously in power.

To 2009-200 years since Darwin's birth, 150 years since publication of Origin of Species. Again, there are calls for changes in evolutionary theory. This time, the calls are met with celebration - we almost beg for an Extended Synthesis, some new and fresh framework that allows us to celebrate our legacy and add new findings to it. The lack of negative emotion may reflect the co-opting and rebranding of controversial concepts suggested by Brooks and Wiley, Eldredge and Gould, and many others. But again, I think this is an incomplete explanation because it does not explain the positive emotion, which I believe is linked to 1982, through a second atavistic reaction- new life from old, the continuation of life, the extension of life into the future, even notions of renewal and resurrection. Humans have long balanced on the knife's edge between understanding personal mortality and deciding to live and reproduce. It's no surprise that the person who changed Darwinism into the much more optimistic neo-Darwinism was Herbert Spencer, deeply committed to racial, social, and economic concepts of human-driven progress. But, as
John Maynard Smith constantly reminded evolutionists, there are no benefits without costs. That is,

The concept of progress acts as a protective mechanism to shield us from the terrors of the future.-Herbert 1965: 321.

I studied the development of evolutionary biology as a scientist searching for critical errors in my thinking. Eldredge $(1985,1995)$ provided the key; Darwinism and neo-Darwinism differ on a number of important issues. Had I been attacking the wrong target, believing that neoDarwinism was wholly Darwinian, throwing the baby out with the bath water?

\section{Back to the Origin}

If a colleague publishes more than once on a topic, we cite the most recent version. Consequently, I cite the sixth edition of the Origin. Effective scientists also write according to the formula, "Tell them what you're going to tell them; tell them; tell them what you told them." Many discussions of Darwinism begin with the final sentence of the sixth chapter of the Origin

Hence in fact the law of the Conditions of Existence is the higher law; as it includes, through the inheritance of former adaptations, that of Unity of Type. (Darwin 1872: 195)

Is this Darwin's thesis that natural selection is the higher law of biology? The statement comes late in the game ("tell them what you've told them"). Prior to it are many pages of empirical information supporting his thesis ("tell them..."), so his thesis ("Tell them what you're going to tell them...") should be near the beginning, perhaps in the second paragraph of the book

There are two factors: namely, the nature of the organism and the nature of the conditions. The former seems to be much more the important; for nearly similar variations sometimes arise under, as far as we can judge, dissimilar conditions; and, on the other hand, dissimilar variations arise under conditions which appear to be nearly uniform. (Darwin 1872: 32)

Darwin's conception of the Nature of the Organism was explicit: it is in the nature of the organism to produce offspring; to produce offspring similar but not identical to each other; to transmit those similarities and differences to their offspring; and to act in their own behalf.

The most important point is that these capacities of the nature of the organism obtained regardless of the Nature of the Conditions. This is Darwin's Necessary Mismatch (Brooks and Hoberg 2007; Brooks 2010a, b; Brooks and 
McLennan 2011). Without a high degree of autonomy from the nature of the conditions, there would be no reproductive overrun, no struggle for survival, no natural selection. For Darwin, natural selection was the outcome of conflicts created a priori by the conditions of existence. It was not the higher law, but one consequence of it. The final paragraph of the sixth chapter of the Origin supplies the essential context

It is generally acknowledged that all organic beings have been formed on two great laws [my italics]unity of type and the conditions of existence... On my theory, unity of type is explained by unity of descent. The expression [my italics] of conditions of existence... is fully embraced by the principle of natural selection... Hence in fact the law [my italics] of the Conditions of Existence is the higher law; as it includes, through the inheritance of former adaptations, that of Unity of Type. (Darwin 1872: 194-195)

The higher law governs the conditions of existence, the sum of interactions between the nature of the organism and the nature of the conditions. Darwin used "conditions" in two different ways. The "nature of the conditions" and "expression of the conditions of existence" refer to material elements in the surroundings, synonymous with current use of "environment," the material circumstances in which conflicts of interest between organisms take place (Maynard Smith and Szathmàry 1995). The "law of the conditions of existence" is more broadly conceptual, even metaphorical.

This perspective emphasizes how unusual Darwinism was. Darwin postulated that evolution was not a process per $s e$, but was an outcome of interactions between two classes of phenomena, each following their own rules yet spatially and temporally entwined. Furthermore, the two classes of phenomena were not co-equal, one was more important than the other. And yet, it is the "greater" phenomenon that inevitably creates conflict, while it is the "lesser" that leads to resolutions of those conflicts. If Darwin were writing today, he would write of complex systems behavior, but in his day and age, it seemed incoherent, muddled, and overly complicated. There were many attempts to "fix" the theory, reaching a crescendo during The Eclipse of Darwinism in 1890-1940 (Bowler 1983). Chief among the competitors were neo-Lamarckism, which proposed that all evolution was due to the influence of the "nature of the conditions," and Orthogenesis, which proposed that all evolution was due to the influence of the "nature of the organism."

\section{Origins of Neo-Darwinism}

Bowler declared that the end of the eclipse of Darwinism began with the rise of neo-Darwinism in the 1920s. I suggest that the eclipse began with Herbert Spencer. Stocking (1983) noted that, by 1871, among anthropologists and sociologists at least, "evolution" was synonymous with progressive historical sequences, and Spencer interpreted the principle of natural selection as a progressivist phenomenon, in which the fittest were those who achieved a better "fit" to their surroundings and thus outcompeted their rivals. As "survival of the fittest" gained popularity, E. D. Cope, an American neo-Lamarckian, raised the following question (Cope 1887): "If evolution is survival of the fittest, what explains the origin of the fittest?" Cope believed only Lamarckian mechanisms could account for the origin of the fittest. Darwinians would have dismissed Cope's arguments because evolution was not survival of the fittest but survival of the adequate (Darwin explained in the sixth edition of the Origin that not all "adaptations" [functions] were evolutionarily significant, and no one should make the mistake of equating fitness with adaptation: Brooks and McLennan 2002). Spencerians responded by making natural selection a creative process. By inextricably linking "fitness" and "progress" and thus "adaptation" and "progress" (later "optimality"), natural selection could be construed as a creative process "progressively" eliminating all less than maximally fit traits. The most effective early proponent of this view was August Weismann, whose ideas traditional Darwinians of the last decade of the nineteenth century derided as "neo-Darwinism" (Hull 1988). If natural selection explained the origin of traits, however, evolutionary theory could be simplified enormously. George Gaylord Simpson (1944) characterized natural selection as a sculptor. With his metaphor of a formless block of marble, Simpson showed the fundamental difference between Darwinism and neo-Darwinism with respect to the nature of the organism. Traditional Darwinians would have characterized different lineages of inheritance as the sculptors and natural selection as more of an art critic.

For Darwin, inheritance, being largely autonomous from the details of the conditions, introduced historical contingency into evolutionary explanations. This perspective was consistent with a Humean interpretation of history as a series of causal events that may influence on the future without assuming the future is pre-determined. This is the reason the Origin includes a picture of a phylogenetic tree indicating open-ended diversification anchored by common ancestry, shown through inheritance. Being progressivist, neo-Darwinism fit well with the view that history is a passive record of the emergence of inevitable events. Morgan (1932) wrote, "...biology is no longer simply a branch of history. It is now a science." Having eliminated the nature of the organism by making selection creative, neo-Darwinists also killed time by eliminating phylogeny as explanatory. 


\section{The Hardened Synthesis}

By the early 1970s, Steven J. Gould noted a Hardening of the Synthesis. Eldredge $(1985,1995)$ eloquently documented how the hardening led to a simple view of evolution, in which function follows the nature of the conditions and form follows function. This blurred the distinction between Darwinian and Lamarckian explanations. In Evolution as Entropy, we suggested that neo-Darwinism had become a sociological label one applied to oneself in order to be considered acceptably mainstream. I present next some statements about evolution I've read or heard in the past 30 years (some in the past six months) by self-described neo-Darwinians, preceded by Darwin's views in the sixth edition of the Origin:

(1) Evolution is the interplay of the nature of the organism and the nature of the conditions, the nature of the organism being far more important became evolution is adaptation by random variation to changing environments;

(2) Phylogeny is a critical part of causal explanations became phylogeny is a passive record of past selection events (more recently, analogous to the error term in an ANOVA model);

(3) Ecology is played out on an evolutionary stage became evolution is played out on an ecological stage;

(4) Species are real and speciation is caused became species are not real and speciation is a demographic accident;

(5) Evolutionary outcomes are generally gradual because evolution is the net outcome of organisms responding to many different aspects of the nature of the conditions (so many selection vectors) became evolution is inherently gradual;

(6) Fitness space is "sloppy" (Agosta and Klemens 2008); most evolutionary dynamics are the result of organisms with non-zero fitness wandering through fitness space became fitness space is highly optimized with fuzzy boundaries, and organisms do not change fitness space without eliminating a less fit occupant;

(7) High levels of variation are expected; all variants with non-zero fitness in the environments in which they are born survive became high levels of variation are not expected; the variant with the highest fitness replaces all others (if there is variation, all variants have the same fitness);

(8) The conservative nature of inheritance and insensitivity of reproduction to the nature of the conditions produce more organisms needing the same resources than there are resources available became limited environmental resources create conflicts;

(9) Survival of the adequate became survival of the fittest;
(10) Survival is paramount (he who lives longest wins) became optimality is paramount (he who dies with the best toys wins).

\section{Ending the Eclipse: Extending in Two Directions}

The eclipse of Darwinism began to end in the 1980s and hangs in the balance today. We need an Extended Synthesis, using "extension" metaphorically. We must extend back in time to recover important aspects of Darwinism that were set aside, then lost during neoDarwinism, then move forward beyond neo-Darwinism to encompass new data and concepts (see also Szathmáry 2006). Three proposals consistent with the goal of ending the eclipse are: The Hierarchy View (Eldredge 1985, 1995): Living systems are simultaneously part of an informational (production) hierarchy of replicators and information flow (the Genealogical Hierarchy-Nature of the Organism) and an energetic (exchanges) hierarchy of interactors and energy flow (the Ecological Hierarchy-Nature of the Conditions). The Information View (Brooks and Wiley 1988): irreversibility in biological systems (reproduction, ontogeny, evolution) results from entropic increases in biological information, constrained by intrinsic (inheritance system informational dynamics-Nature of the Organism) and extrinsic (selection-Nature of the Conditions) cohesive properties. The Evolutionary Transitions View (Maynard Smith and Szathmàry 1995): Evolutionary Transitions increase the efficiency of storing and transmitting information (Nature of the Organism), thereby enhancing organism/ environment interactions (Nature of the Conditions). The last is the most comprehensive framework relative to an Extended Synthesis; there is even a teaching text available (Maynard Smith and Szathmàry 1999).

The Extended Synthesis rests comfortably within a philosophical perspective called the Autonomy of BiologyBiology does not need to be connected with other areas of science in order to justify itself. I am attracted to an older concept called the Unity of Science-Biology needs a covering law to connect it with the rest of the natural sciences. Darwin implicated a "higher law," but did not specify it

"Hence in fact the law [my italics] of the Conditions of Existence is the higher law..." (Darwin 1872: 195)

I believe that if we can elucidate that covering law, the Extended Synthesis will become the Unified Theory of Biology called for by Brooks and Wiley $(1986,1988)$.

Acknowledgments This work was done during the tenure of a Visiting Senior Fellowship at the Collegium Budapest (Institute for Advanced Study) in Budapest, Hungary. I thank the staff and 
colleagues of the Collegium, who have freely shared so many ideas and perspectives with me. In particular, I thank Eors Szathmary, whose intellectual breadth and depth is breathtaking, exceeded only by his sense of humor and infectious joy of learning. My thanks also go to Niles Eldredge for producing such a progressive forum for evolutionary biology.

\section{References}

Agosta SJ, Klemens JA. Ecological fitting by phenotypically flexible genotypes: implications for species associations, community assembly and evolution. Ecol Lett. 2008;11:1123-34.

Bowler PJ. The eclipse of Darwinism. Baltimore: Johns Hopkins University Press; 1983.

Brooks DR. The unified theory, macroevolution, and historical ecology. In: Baas P, editor. The plant diversity of Malesia. Amsterdam: Kluwer; 1990. p. 379-86.

Brooks DR. Incorporating origins into evolutionary theory. In: Varela F, Dupuy JP, editors. Undertsanding origin: contemporary ideas on the genesis of life, mind and society. Amsterdan: Reidel/ Kluwer Assoc; 1992. p. 191-212.

Brooks DR. Entropy, information and evolving biological systems. Theor Hist Scient. 1994;4:31-49.

Brooks DR. Biological evolution as a microcosm of cosmological evolution. Bridges. 1997;4:9-35.

Brooks DR. The unified theory of evolution and selection processes. In: van de Vijver G, Salthe SN, Delpos M, editors. Evolutionary systems: biological and epistemological perspectives on selection and self-organization. Dordrecht: Kluwer; 1998. p. 113-28.

Brooks DR. Evolution i informationsåldern: livet får ett eget liv. Carpe Scient. 1999;2:14-5.

Brooks DR. The nature of the organism: life takes on a life of its own. Proc N Y Acad Sci. 2000;901:257-65.

Brooks DR. Diversity, organismal level. In: Levins S, editor. Encyclopedia of biodiversity. Vol. 2. New York: Academic; 2001a. p. 191-207.

Brooks DR. Evolution in the information age: rediscovering the nature of the organism. Semotics Evol Ener Devel. 2001b;1:1-26. Available at: http://www.library.utoronto.ca/see.

Brooks DR. Taking evolutionary transitions seriously. Semotics Evol Ener Devel. 2002;2:6-24. http://www.library.utoronto.ca/see.

Brooks DR. Sagas of the children of time: the importance of phylogenetic teaching in Biology. Evo Edu Outreach. 2010a;3:495-8.
Brooks DR. The mastodon in the room: how Darwinian is neoDarwinism? Studies in history and philosophy of biological and biomedical sciences. 2010b. doi:10.1016/j.shpsc.2010.11.003.

Brooks DR, Hoberg EP. Darwin's necessary misfit and the sloshing bucket: the evolutionary biology of emerging infectious diseases. Evol Edu Outreach. 2007;1:2-9.

Brooks DR, McLennan DA. Searching for a general theory of biological evolution. J Ideas. 1990;1:35-46.

Brooks DR, McLennan DA. Phylogeny, ecology and behavior: a research program in comparative biology. Chicago: University of Chicago Press; 1991.

Brooks DR, McLennan DA. Biological signals as material phenomena. Rev pensee 'aujord 'hui. 1997;25:118-27.

Brooks DR, McLennan DA. The nature of the organism and the emergence of selection processes and biological signals. In: Taborsky E, editor. Semiotics, evolution, energy. Aachen: Shaker Verlag; 2000. p. 185-218.

Brooks DR, McLennan DA. The nature of diversity: an evolutionary voyage of discovery. Chicago: University Chicago Press; 2002.

Brooks DR, McLennan DA. Diversity, organismal level. In: Levins S, editor. Encyclopedia of biodiversity. Vol. 3: 00-000. New York: Academic; 2011.

Brooks DR, Wiley EO. Evolution as entropy: toward a unified theory of biology. 2nd ed. Chicago: University Chicago Press; 1988.

Cope ED. Origin of the fittest: essays on evolution. New York: D. Appleton and Company; 1887.

Darwin C. The origin of species. 6th ed. London: John Murray; 1872.

Eldredge N. Unfinished synthesis. New York: Columbia University Press; 1985.

Eldredge N. Reinventing Darwin: the great debate at the high table of evolutionary theory. New York: Wiley; 1995.

Herbert F. Dune. New York: Penguin-Putnam; 1965.

Hull DL. Science as a process: an evolutionary account of the social and conceptual development of science. Chicago: University Chicago Press; 1988.

Maynard Smith J, Szathmàry E. The major transitions in evolution. Oxford: W.H. Freeman; 1995.

Maynard Smith J, Szathmàry E. The origins of life. Oxford: Oxford University Press; 1999.

Morgan TH. The scientific basis of evolution. New York: W.W. Norton \& Company; 1932.

Simpson GG. Tempo and mode in evolution. New York: Columbia University Press; 1944.

Stocking GW Jr. Race, culture and evolution: essays in the history of anthropology. Chicago: University of Chicago Press; 1983.

Szathmáry E. Evolution. Darwin for all seasons. Science. 2006;313:306-7. 